\title{
Organizations in a Non-Linear, Unpredictable World
}

\author{
Pirjo Ståhle ${ }^{1}$, Leif Åberg ${ }^{2}$ \\ ${ }^{1}$ Visiting Professor of Knowledge and Innovation Management, School of Engineering, Aalto University, Finland \\ ${ }^{2}$ Professor Emeritus of Organizational Communication, Department of Social Research, University of Helsinki, Finland \\ Correspondence: Pirjo Ståhle, Visiting Professor of Knowledge and Innovation Management, School of Engineering, \\ Aalto University, Finland
}

Received: January 15, 2015 Accepted: January 28, 2015 Online Published: February 9, 2015

doi:10.11114/bms.v1i1.667

URL: http://dx.doi.org/10.11114/bms.v1i1.667

\begin{abstract}
Globalisation, new information technology, universal networking, the non-linearity of things, and environmental turbulence are changing strategies of managing and succeeding. This paper examines non-linear phenomena and their practical consequences from an organizational perspective by using three concepts: Malcolm Gladwell's tipping point, Ilya Prigogine's self-organization, and Algirdas Greimas's semiotic square. Tipping points occur at all system levels, determining for instance how fashion trends catch on, how health campaigns succeed, and how new ideas spread like wildfire. Self-organization refers to the kind of consciousness, action and intelligence that is manifested in the community's rather than the individual's actions, such as swarm intelligence in the animal world. Insight into the dynamics of change is supplemented by the semiotic square, which sheds light on how organizations can succeed. Organizations must have buffers, a surplus of resources to which they can resort whenever something unexpected happens, and they must be attuned to change and have access to tools that promote open, confidence-building communication.
\end{abstract}

Keywords: non-linearity, tipping point, self-organization, semiotic square, dynamics of change

\section{Introduction}

Recently, we have heard from the news how an ill-conceived video trailer (Sam Bacile's Innocence of Muslims) caused mass rioting and bloodshed throughout the Islamic world; how a birthday party invitation posted on Facebook by a teenage girl brought the small Dutch town of Haren to the brink of chaos; and how the board of Finnish engineering giant Metso, in the process of laying off thousands of employees, had to withdraw its payout of extra dividends to shareholders following a public outcry. These three examples are seemingly very different, but they have one thing in common: they all reached tipping point - the moment beyond which things are irrevocably changed and different.

Globalization, new information technology, universal networking, the non-linearity of things, and environmental turbulence are shifting and changing the overall dynamics of the world. The consequences can be seen at all levels of social life: at the individual, organizational and (inter)national level. Management by control is becoming ever less effective; management today is more about navigation than control, and work is more closely akin to surfing than mechanistic implementation of plans. Organizations have transformed from rigid, mechanistic structures into organic and dynamic systems that can quickly adapt to changing circumstances and that are capable of self-organization (Ståhle 2003, Malaska 1991).

This paper aims to provide insight into the changes that have happened in the dynamics of the world and to explore some of the new challenges these changes present for organizations. We examine these non-linear phenomena by using three concepts: Malcolm Gladwell's tipping point, Ilya Prigogine's self-organization, and Algirdas Greimas's semiotic square.

\section{Tipping Point - Sudden, Powerful, Uncontrollable}

The tipping point - how little things can make a big difference by American science journalist Malcolm Gladwell came out in the year 2000. Tipping points occur at all system levels: global, societal, organizational, individual. In his book Gladwell describes a number of tipping-point occurrences, such as how fashion trends catch on, how health campaigns succeed, and how new ideas spread like wildfire. He says these phenomena seem to share three key factors in common: stickiness, the law of the few (butterfly effect) and dramatic impacts in a proper context. 
Tipping-point phenomena are sticky because they intrigue people either as problems or opportunities concerning themselves, but also because they are actively disseminated. They are most likely to reach tipping point if they are advocated by three kinds of people: connectors, mavens or information specialists, and salesmen or persuaders. Connectors have extensive social networks and therefore can make things happen very quickly. Mavens know how to explain things to other people. Salesmen, then, are charismatic individuals who radiate a positive, inspirational energy.

Tipping-point phenomena are based on what is known as the butterfly effect, a principle which says that small causes can have large consequences. Coined by meteorologist Edward Lorenz (1961), the famous metaphor is that the flap of a butterfly's wings in Brazil can set off a tornado in Texas. A discussion between two persons can start a popular grassroots movement (pop-up restaurant day in Finland), one book can eradicate slavery (Uncle Tom's Cabin) and the protest of one man can lead to national revolutions (Tunisian street vendor Mohamed Bouazizi's suicide by immolation during the Arab Spring 2011). Tipping points are always the outcome of complex cause-and-effect relationships, which may quickly reinforce one another and unfold like a domino effect from one small push.

Tipping-point effects are always context-bound and dramatic: things are never the same afterwards. When a dictator has been deposed, society will reorganize itself. When a radical innovation is introduced in the marketplace, the market is irrevocably changed. There is nothing new about the phenomenon itself; there have always been tipping points. However, today's social media have made tipping points much more common and easier: it's now possible for anyone to raise issues, to persuade public opinion, to mobilize the masses. Things reach tipping point, appear without warning, when they are least expected.

Human interaction has become ever more complicated. Universal networking, the non-linearity of things, environmental turbulence, and the constant occurrence of various tipping points have changed strategies of managing and succeeding at all levels of society. These changes place enormous demands on the skills and competencies of individuals, but also on organizations that are keen to thrive in an unpredictable world. In this situation it seems that a new framework of practice is emerging that is based on the capacity of systems for self-organization.

\section{Navigating from Chaos to Dynamic Balance}

Self-organization refers to the kind of consciousness, action and intelligence that is manifested in the community's rather than the individual's actions - in the same way as swarm intelligence in the animal world. A police anti-terrorist squad, a football team or an ICU team are good examples of how close and intense interaction generates collective consciousness.

One of the distinctive features of our increasingly non-linear and unpredictable world is the growth of chaos. Chaos and the crises that follow are traditionally thought of as negative, unwanted phenomena that should be avoided at all cost. In this article we shed light on the other side of chaos: that is, every crisis also has a new opportunity built into it. This principle was known even in ancient China. In the Chinese language, the word crisis is made up of two characters: danger and opportunity.

In their book Organize with Chaos, Robin Rowley and Joseph Roevens (1996) propose an organization model in which chaos is a built-in element. They maintain that the traditional line organization was explicitly designed to resist change - or at least to afford greater predictability. In today's ever-changing, unpredictable environment, however, line organizations are far too rigid. In Rowley and Roevens's model the constant balancing between chaos and order creates an element of tension (Fig. 1). According to their model it is not possible for organizations to function only in a rational, planned and controlled manner, because they are always subject to a host of unpredictabilities. In today's networked, global operating environment, surprises or unexpected events are not just isolated anomalies, but unpredictability is the normal state of affairs. That is why, Rowley and Roevens maintain, the element of chaos must be woven into the organization's practices and operations from the very outset. What this means in practice is that in all its planning, the organization must be prepared for the unexpected. It must therefore have mechanisms in place that will allow it to operate in conditions of chaos or on the brink of chaos and to navigate out of chaos into a new, more dynamic balance

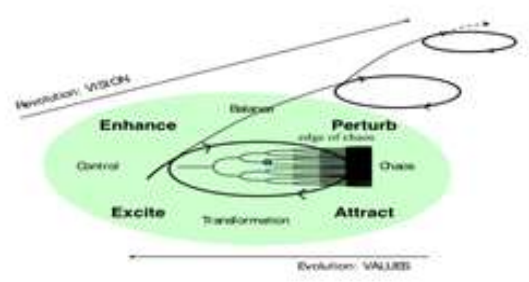

Figure 1. Rowley and Roevens's model of change (1996) modified by the authors 
In a balanced organization things are under control, although not so rigorously as to prevent agile reaction to internal and external changes. When the opportunity presents itself, the organization must be in the position to take risks and have the audacity to make tiger leaps.

The organization's balance can be unsettled either from within or from the outside environment. Internal factors might include the CEO's sudden and unexpected paralysis or departure, fire, sabotage or a new, revolutionary innovation. Examples of external factors include a change of legislation, the appearance of a strong competitor in the marketplace, natural disasters, sudden threats to reputation or a momentary window of opportunity.

The balancing between chaos and control can also be described by the bifurcation model proposed by chaos theorist Robert May (1976). Bifurcation refers to a process called period-doubling: the state or behaviour of a system is suddenly divided into two sub-behaviours or two states. This means a new line of action appears alongside the old one, adding to the diversity of the system. As new lines of action continue to emerge, the organization moves closer to the edge of chaos. This is exactly how the plot unfolds in disaster movies, for instance: there is ever-escalating disorder and confusion as no one really seems to know what other people are doing. All communication has broken down. Even though most people might be behaving rationally from their own point of view, other parallel events may cancel that out. Fortunately at the end of the movie someone - usually a summer trainee - will step up, take control and begin to re-establish order, which gradually leads to a new way of doing things. Consequently the organization begins to move towards a state of control again, although it is significantly different from the initial situation. However, balancing between chaos and control is a building block not only of the drama of movies, but an important part of the lives of modern-day people and organizations. As the environment has become ever more turbulent, so resilience and self-organization have become necessary success factors. What does this mean in practice?

\section{A System is Capable of Self-Organization If ...}

In the 1960s Belgian chemist and Nobel Prize laureate Ilya Prigogine undertook groundbreaking work on self-organizing systems. He, too, stressed that chaos is not an exceptional, but a perfectly normal systemic phenomenon. Furthermore he pointed out that despite this, not all systems are capable of self-organization: this is only possible if certain conditions are met. In the absence of these conditions, chaos will only lead to disorganization, without anything new being created.

Prigogine published his work on dissipative or self-organizing systems in 1967 . He used these systems to study the process of becoming and the evolution of order out of chaos. His results indicated that in certain circumstances, systems were capable of self-organization unpredictably and without external control (e.g. Prigogine 1967, 1980; Prigogine \& Stengers 1984, Prigogine \& Nicolis 1989). According to Prigogine, most systems occurring in the world are capable of self-organization when certain conditions are met. Applied to organizations, these conditions could be described as follows: 1) the organization must be in a far from equilibrium state; 2) it must produce entropy, an abundance of 'unnecessary' or 'superfluous' information; 3) it must be capable of iteration, i.e., provide immediate feedback and respond quickly and flexibly to feedback received; and 4) it must be sensitive to the opportunities created by situations and dare to take action when the time window is open. The following sections examine these four conditions in some more detail (for a more in-depth discussion, see Ståhle 1998 \& 2008; Poutanen \& Ståhle, 2014).

In all forms of life, chaos or being far from equilibrium is the source of new order. The key foundation of all self-organizing systems is an abundant exchange of information, i.e. abundant and uncontrolled interaction, which in itself brings dynamism and disorder to the system. A self-organizing system lives constantly in the alternating rhythm of chaos and order.

Entropy plays a critical role in producing chaos. Entropy refers to energy or information that is produced by the system but that ultimately has no use; it is effectively unnecessary, superfluous energy or information. The phenomenon is familiar to us from creative processes in which we collect and amass much material that will ultimately prove useless to the solution or end-result. However abundance of information is necessary for the solution to take shape. A high degree of entropy is also indicative of disorder: a situation where it is impossible to know what is good or bad, right or wrong. This, in turn, brings uncertainty, imbalance and confusion into the organization, i.e. the very element of instability that makes self-organization possible in the first place. Prigogine specifically points out that self-organization can only occur in systems that are far from equilibrium and where that disequilibrium can be maintained through internal communication. Both the quantity and quality of communication are crucial to self-organization. It is not enough for information to trickle from the top down; interaction must be non-linear, i.e. interactive, challenging and constructively critical.

Iteration is a continuous, highly sensitive feedback process. It allows for the rapid dissemination of information and models throughout the system. Iteration gives the system its ability to copy internal models from the micro to macro level and vice versa. Iteration makes the system spontaneous and sensitive to changes. This is manifested in the 
butterfly effect: initially the effect will be seen in just a small part of the system, but it will then advance and gather momentum and potentially lead to sudden and radical tipping points. This would not be possible without the sensitive and constant interaction between different parts of the system. Small-scale piloting and the rapid and wide-scale dissemination of its experiences provide one example of iteration.

The self-organization of practices and structures follows its own timing rules, which means that crucial steps and decisions cannot be taken at just any time. Bifurcation, according to Prigogine, means that a) there are certain periods in the life of an organization when it can makes choices, and other periods when it cannot make choices; b) the outcome of choices cannot be predicted; and c) these choices are irreversible. Bifurcation always produces a new situation that is not a logical extension of the previous state and that is more diverse than the previous state. The event of bifurcation, therefore, is also always a source of innovation.

The transition from chaos to order brings about loss of diversity. In this stage the system focuses on information that it assumes is relevant, thus rejecting a vast amount of information, reducing the amount of entropy and paving the way to a new order. The changeover to a new state of equilibrium happens suddenly, as if in a single quantum leap. The point of bifurcation marks the sudden realization that things can be completely different from what has been previously assumed. In the individual's life this finds its most concrete expression in the familiar sense of sudden insight or inspiration: all of a sudden everything is perfectly clear and obvious. As recent brain research has shown, the human brain functions largely on the principles of self-organization (Singer 2009 \& Kelso 1997).

The development of systems that are capable of self-organization therefore includes both stable stages dominated by deterministic laws, and unstable stages or points of bifurcation where the system can choose to follow completely new paths of development. Entropy produces abundance and chaos in the organization, with points of bifurcation both creating new order and equipping the system with new characteristics and structures. This kind of evolution is built into the self-organizing organization: it is the system's way of being. In the natural environment, in human life and in organizations, entropy produces constant development and forward movement, which has both an innovative and a deterministic side. People live their lives on the interfaces of both necessity and opportunities, of being and becoming. ${ }^{1}$

\section{There is Good Order and Bad Order-Just as There Is Good Chaos and Bad Chaos}

What is the current dynamics of change, right now at this moment: are we heading towards order or towards the edge of chaos? How do we know? There are many signs that offer important clues. Students attending the Management and expert communication course at the University of Helsinki in spring 2012 were given the task of identifying them. These students thought that the dynamics is headed towards the edge of chaos when there is a tendency to form cliques and alliances, when the tone of discussions around coffee tables begins to change or when rumours begin to circulate. The team spirit begins to wilt. The volume of communication either increases exponentially or grinds to a sudden halt. Stress and time pressures begin to escalate, sickness absences and dismissals increase. Management is felt to be distant. Customer satisfaction declines, sales plummet. The process moves towards new order by the time that agreement is reached on new goals that people feel they can commit themselves to, or when clarity is reached about the division of labour or job roles. There is more mutual sparring and helping. Absenteeism and overtime will both be on the decline. Discussions will have a more optimistic tone. Sales will rebound and the new product launched into the marketplace will be a great success.

It is interesting - but not surprising - that all the signs of chaos identified by our students in Helsinki were negative. However, as Prigogine points out, chaos is also produced by positive things, such as open communication which highlights diverging interests and contradictory perspectives, or brainstorming sessions where new ideas are floated without any pressures to make decisions or to assess their viability. It is also noteworthy that most of the signals identified by our students have to do with communication and interaction among members of the organization - a view that is fully in line with the argumentation of Prigogine and other scholars in this field.

As we reflected on the dynamics of change, it became increasingly clear to us that neither Rowley and Roevens's model nor that advanced by Prigogine provided the tools we needed to describe the life of an organization in a state between order and chaos. That is, order can be either a good thing or a bad thing. Good order points the way out of bad chaos. It makes it possible to run an efficient operation and lays the foundation for flexibility and for new initiatives. Bad order confines and restrains. It introduces rigidity into the organization, forces it to follow old routines even when they might not be at all appropriate in the new situation. The same goes for chaos; there is both wanted and unwanted chaos. Chaos may be a necessary stage on the path of development, a gateway to new opportunities and innovations. On the other hand chaos may bring the organization to a state of fragmentation where every step only makes matters worse.

\footnotetext{
${ }^{1}$ Other models describing dynamics of complexity from management perspective are found in e.g. Stacey, Griffin and Shaw (2000) and Aula and Åberg (2013)
} 
We found the solution to our deadlock in semiotics, particularly the semiotic square developed by Lithuanian Algirdas Greimas $^{2}$. Semioticians often work with the tools of polarization and binary oppositions. Examples of such binary oppositions are above/below, front/behind and life/death. Greimas's semiotic square provides us with an excellent tool for analyzing these kinds of oppositions. Applying the semiotic square (Fig. 2) to organizational dynamics, we can start out from the top left hand corner with the assertion of GOOD ORDER. Contradicting this concept is the non-concept BAD ORDER, which we place in the lower right hand corner. In the upper right hand corner we have the negation of good order, which could be BAD CHAOS. Contradicting that concept is the non-concept of GOOD CHAOS, which we place in the lower left hand corner ${ }^{3}$.

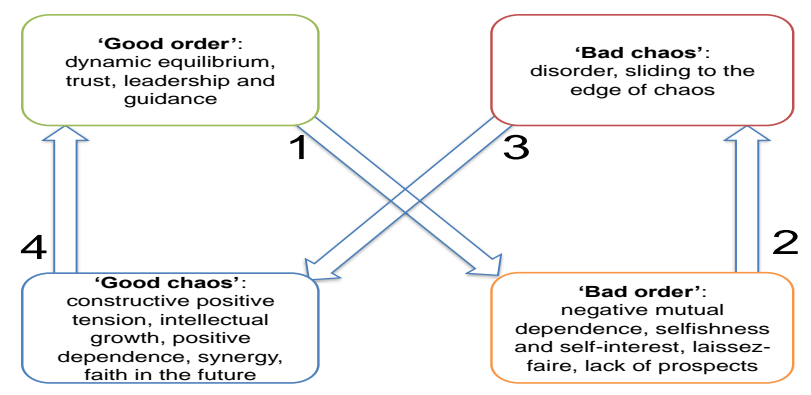

Figure 2. Gahmberg and Åberg's model of change (Åberg 1999)

This allows us to theoretically construct the organization's learning and development cycle. That cycle starts out from good order and proceeds through bad order to bad chaos, which then brings us via good chaos to good order again. A well-ordered workplace community is in a state of dynamic equilibrium, i.e. its internal processes are compatible with the requirements of the environment. This state does not last forever, however, because the environment is in constant flux, for instance when a new, superior competitor appears in the marketplace or when the general economic climate deteriorates. Things may also happen within the workplace community that cause it to lapse into bad order. Changes in management strategies or ownership arrangements may lead to changes in personnel and job uncertainty. The workplace community is thrown into a state of bad order, which is characterized by negative mutual dependence, a pressing atmosphere, selfishness and self-interest, lack of prospects and a spirit of laissez-faire. Bad chaos is always characterized by breaks in interaction, deteriorating relationships in the workplace and the growth of distrust. As a result the organization loses its ability to take advantage of chaos for self-organization and moves increasingly towards a state of fragmentation.

What, then, is communication like in this awkward transitional stage? All might start from one surprising, negative signal coming from the environment. If that signal elicits a panic-like response, rumours and contradictory information will begin to circulate about the state of the workplace community. Information is withheld. Actions and messages are incompatible as assurances are made that everything is fine, that there are no problems (Table 1).

The state of bad chaos is a state of disorder. No one knows what other people are doing. The workplace community lacks coherence and predictability. The difference between bad order and bad chaos lies in panic-stricken behaviour. Panic ensues when lots of people, under severe time pressure, make wrong and contradictory choices, when people run out of steam and ideas, when their tolerance begins to give out and in defence they curl up in the present moment and current routines. However the depth of resources from which people can draw at moments of extreme distress is quite amazing. These are the moments when the heroes of great stories take centrestage. They might be one of the "village idiots' from within the organization who has never been given any serious attention before. You will find them in every company: Rowley and Roevens call them true rebels. They might also be a conciliator who has the patience and tolerance to mediate between disputing parties. Or they might be just anyone with a vision and the know-how to inspire

\footnotetext{
${ }^{2}$ Greimas first presented the square in Semantique Structurale (1966), a book which was later published as Structural Semantics: An Attempt at a Method (1983). He further developed the semiotic square with Francois Rastier in "The Interaction of Semiotic Constraints" (1968).

${ }^{3}$ It might be easier to grasp the semiotic square if we use more familiar concepts. If we start out from the concept of life, its contrary or non-concept is non-life and its negation is death. The non-concept of death is non-death. In other words a person who is not living is either dead or not alive (i.e. not dead but not leading a life worth living such as Nora in Henrik Ibsen's A Doll's House). The semiotic square is a good way of trying out different concepts and expressions. For instance, the negation of fat is thin, but if you are in the business of marketing slimming pills, for instance, you might want to use some other non-fat concept (say normal or well-shaped?), because not all fat people want to be anorexic, they just don't want to be fat! Pedantry? Not at all!
} 
faith in the organization's ability to get out of the rut in which it is stuck. The vision provides this direction. The vision can also look further ahead to the future, giving people the support and strength they need to get out of their predicament. The key is to restore a sufficient degree of trust among people so that genuine interaction is made possible again and people can actually get hands on. This will lead to the transition from bad chaos to good chaos.

\begin{tabular}{cl}
\hline \multicolumn{1}{c}{ Phase } & \multicolumn{1}{c}{ Signs } \\
\hline 1 From good order to bad order & $\begin{array}{l}\text { competition, balance unsettled, increasing uncertainty about jobs, } \\
\text { personnel changes, constant changes in management practices, } \\
\text { withholding of information, rumours rife, underestimation of } \\
\text { problems, increased absenteeism }\end{array}$ \\
lack of tolerance, energy and ideas run out, wrong business decisions, \\
panic solutions, reverting to old practices \\
increased faith in vision that shows the way out, ideas of 'true rebels' \\
are taken seriously, increased tolerance \\
legitimate vision provides direction, increased commitment and \\
engagement, increased internal interaction and trust
\end{tabular}

Good chaos differs essentially from bad chaos. Actions taken in a state of good chaos involve a built-in positive tension - at this point there are no proven models or strategies because the search for them has only just started. The keyword is synergy: the type of resource use in which tacit knowledge and skills emerge as the driving force. Intensive information exchange brings a temporary increase in uncertainty and confusion, but if the organization can tolerate that, the interaction will eventually lead towards a point of bifurcation. As a result new order will be created, possibly even a new vision for the organization.

Good chaos thus leads to good order. Once a legitimate vision has been created as a result of broadly based interaction, commitment to that vision is not a problem. In fact legitimacy is precisely about debating whether we are doing the right things and doing them in the right way. It is apparent that at this stage, the workplace community needs a guide not a manager but a leader - who has the capacity to develop visions and the ability to inspire other people and get them onboard. The vision gains internal legitimacy through internal interaction. If people within the company do not have faith in where the organization is heading, it will quickly descend from good order into bad chaos.

\section{From Survival Mode to the Mode of Success}

The world is changing, whether we want it to or not. In this changing world we need a new kind of consciousness and understanding of the new dynamics of things, as well as the ability to create new tools to survive, manage and succeed in the new, non-linear environment. The better we understand the phenomena of tipping points and self-organization, the better use we will be able to make of the opportunities they offer. From the organization's point of view, it is essential that changes are made to ways of managing. Old control-based structures are no longer fit for purpose. Instead, an organization must be seen as a dynamic system that is created by communication. Top-down instructions are not enough, but there must also be horizontal and bottom-up communication. The less communication is determined by hierarchical structure, the better. Without abundant interaction and open communication, all chaos is bad chaos and will only lead to dispersion rather than to a new structure via self-organization.

So what kind of an organization can succeed in this new environment? It needs to have buffers, a surplus of resources to which it can resort whenever something unexpected happens. It needs to be proactive. The prevailing culture should be attuned to change. The organization needs to have access to tools with which to engage in open, confidence-building communication and to harness abundant information exchange as a driving force. Modern technology allows for the mining, collection and storing of vast quantities of data. However the aim is not just to achieve a more efficient use of visible information, but above all to put tacit know-how and experiences into circulation. Organizations should also work to strengthen leadership and to facilitate networking. This will pave the way to the emergence of new, socially produced knowledge and the gradual evolution of collective consciousness in the workplace (Ståhle \& Grönroos 2000).

In the modern world tipping points occur more and more often; individuals, organizations and societies get caught unawares. Successive crises, the good and the bad, follow one another and are an integral part of our everyday life. It's up to ourselves how well equipped we are to deal with them. 


\section{References}

Aula, P. \& Åberg, L. (2013). Blistering Publicities: A New Challenge for Organizational Communication and Public Relations. http://www.mv.helsinki.fi/home/aula/Aula-Aberg-Blistering-Publicities.pdf

Gladwell, J. (2000). The tipping point - how little things can make a big difference. Little, Brown \& Company.

Greimas, A. J., \& Rastier, F. (1968). The Interaction of Semiotic Constraints. Yale French Studies, 41, 86-105. http://dx.doi.org/10.2307/2929667

Kelso, S. J. A. (1997). Dynamic Patterns:The Self-organization of Brain and Behavior. MIT Press.

Lorenz, E. (1963). Deterministic non periodic flow. Journal of Atmospheric

Malaska, P. (1991). Economic and Social Evolution: The Transformational Dynamics Approach. In Publication Ervin Laszlo (ed.): The New Evolutionary Paradigm: The World Futures General Evolution Studies, 2. The Vienna Academy for Global and Evolutionary Studies, Austria, ISBN 2-88124-375-4

May, R. M. (1976). Simple mathematical models with very complicated dynamics. Nature, 261(5560), 459-467. http://dx.doi.org/10.1038/261459a0

Poutanen, P., \& Ståhle, P. (2014). Using self-renewal and complexity framework to examine the work processes in short-term self-directed innovagtion groups. The International Journal of Complexity in Leadership and Management IJCLM, 2(4), 259-277.

Prigogine, I., \& Nicolis, G. (1989). Exploring complexity: An introduction. New York: Freeman.

Prigogine, I., \& Stengers, I. (1984). Order out of chaos: Man’s dialogue with nature. New York: Bantam.

Prigogine, I. (1967). Introduction to thermodynamics of irreversible processes (3rd. ed.). New York: Wiley

Prigogine, I. (1980). From being to becoming: Time and complexity in the physical sciences. San Francisco: Freeman.

Rowley, R. M., \& Roevens, J. J. (1996, 2007) Organize with chaos. Lint: Management Books. Science, 20, 130-141. http://dx.doi.org/10.1175/1520-0469(1963)020<0130:DNF>2.0.CO;2

Singer, W. (2009). The Brain, a Complex Self-organizing System. European Review, 17(2), 321-329. Academia Europæa.

Stacey, R. D., Griffin, D., \& Shaw, P. (2000) Complexity and management: Fad or radical challenge to systems thinking? London, UK: Routledge.

Ståhle, P., \& Grönroos, M. 2000. Dynamic Intellectual Capital-Knowledge Management in Theory and Practice. WSOY: Porvoo, Helsinki, Juva

Ståhle, P. (1998). Supporting a System’s Capacity for Self-renewal. Helsinki, Yliopistopaino.

Ståhle, P. (2008). The dynamics of self-renewal: A systems-thinking to understanding organizational challenges in dynamic environments. IN: Bounfour, A. (Ed.) Organizational Capital: Modelling, measuring and contextualizing. London, Routledge.

Ståhle,P., Ståhle,S., \& Pöyhönen, A. (2003). Analyzing Organization's Dynamic Intellectual Capital. A System-based theory and application. Acta Universitatis Lappeenrantaensis 152.

Åberg, L. (1997). Viestinnän strategiat. Inforviestintä. Helsinki.

\section{$(\mathrm{cc})$ EY}

This work is licensed under a Creative Commons Attribution 3.0 License. 